\title{
Neck pain patients' preference scores for their current health
}

\author{
Gabrielle van der Velde • Sheilah Hogg-Johnson • \\ Ahmed M. Bayoumi · Pierre Côté • Hilary Llewellyn-Thomas • \\ Eric L. Hurwitz $\cdot$ Murray Krahn
}

Accepted: 6 February 2010/Published online: 27 March 2010

(C) The Author(s) 2010. This article is published with open access at Springerlink.com

\begin{abstract}
Purpose To elicit neck pain (NP) patients' preference scores for their current health, and investigate the association between their scores and NP disability.

Methods Rating scale scores (RSs) and standard gamble scores (SGs) for current health were elicited from chronic NP patients $(n=104)$ and patients with NP following a motor vehicle accident $(n=116)$. Patients were stratified into Von Korff Pain Grades: Grade I (low-intensity pain, few activity limitations); Grade II (high-intensity pain, few activity limitations); Grade III (pain with high disability levels, moderate activity limitations); and Grade IV (pain
\end{abstract}

G. van der Velde $(\bowtie) \cdot$ M. Krahn

Toronto Health Economics and Technology Assessment

(THETA) Collaborative, University of Toronto, Leslie Dan Pharmacy Building, 6th Floor, Room 658, 144 College Street,

Toronto, ON M5S 3M2, Canada

e-mail: gabrielle.vandervelde@ theta.utoronto.ca

G. van der Velde $\cdot$ S. Hogg-Johnson

Institute for Work \& Health, Toronto, Canada

S. Hogg-Johnson - A. M. Bayoumi - P. Côté · M. Krahn Department of Health Policy, Management and Evaluation, University of Toronto, Toronto, Canada

S. Hogg-Johnson · P. Côté

Dalla Lana School of Public Health, University of Toronto,

Toronto, Canada

\section{A. M. Bayoumi}

Centre for Research on Inner City Health, Keenan Research

Centre, Li Ka Shing Knowledge Institute of St. Michael's

Hospital, Toronto, Canada

\author{
A. M. Bayoumi \\ Department of Medicine, University of Toronto, Toronto, \\ Canada
}

with high disability levels, several activity limitations). Multivariable regression quantified the association between preference scores and NP disability.

Results Mean SGs and RSs were as follows: Grade I patients: 0.81, 0.76; Grade II: 0.70, 0.60; Grade III: 0.64, 0.44; Grade IV: $0.57,0.39$. The association between preference scores and NP disability depended on type of NP and preference-elicitation method. Chronic NP patients' scores were more strongly associated with depressive symptoms than with NP disability. In both samples, NP disability explained little more than random variance in SGs, and up to $51 \%$ of variance in RSs.

\footnotetext{
A. M. Bayoumi

Division of General Internal Medicine, St. Michael's Hospital, Toronto, Canada

P. Côté

Toronto Western Research Institute, Toronto Western Hospital, Toronto, Canada

H. Llewellyn-Thomas

Department of Community and Family Medicine, Dartmouth Medical School, Dartmouth College, Hanover, NH, USA

E. L. Hurwitz

Department of Public Health Sciences, John A. Burns School of Medicine, University of Hawaii at Mānoa, Honolulu, HI, USA

M. Krahn

Division of Decision Making and Health Care Research, Toronto General Research Institute, University Health Network, Toronto, Canada

M. Krahn

Faculty of Pharmacy, University of Toronto, Toronto, Canada

M. Krahn

Toronto General Hospital, Toronto, Canada
} 
Conclusion Health-related quality-of-life is considerably diminished in NP patients. Depressive symptoms and preference-elicitation methods influence preference scores that NP patients assign to their health.

Keywords Health status · Health-related quality-of-life · Neck pain $\cdot$ Rating scale $\cdot$ Standard gamble .

Utility measurement

\section{Introduction}

Neck pain is a common and burdensome condition costing millions of dollars annually in compensation and treatment [1-5]. Despite an extensive scientific literature, the optimal treatment for neck pain remains uncertain [6]. One approach to evaluating treatments when there are associated risks or uncertainties is decision-analytic modelling [7-9]. A decision-analytic model quantifies trade-offs inherent in alternative treatment strategies, often including treatment benefits, adverse events, inconveniences, and costs.

Preference-based measures of health-related quality-oflife (HRQoL) (or utilities) are important inputs into clinical decision analyses. In health-related applications, these measures quantify individuals' values about the desirability of health states along a scale, usually anchored at 0 , corresponding to death, and 1, corresponding to good health $[7,10]$. Resulting scores are used as weights to calculate quality-adjusted life years in economic evaluations and are also useful to compare the relative impact of disease states $[10,11]$

The only source of directly elicited preference scores for neck pain is the Beaver Dam Health Outcomes Study [1216]. However, certain features of this study limit the validity of its preference scores for decision or costeffectiveness analyses of neck pain treatments. First, the characteristics of the respondents with neck pain, including type of neck pain, were not described. Second, a notable portion of respondents were not likely to be experiencing neck pain when surveyed, since scores were elicited from persons affected by neck pain in the past year, and spine pain (whether cervical or lumbar) has a relapsing and remitting course [2, 17-20]. Third, respondents only included persons affected by severe neck pain, whereas most persons seeking treatment for neck pain have mild to moderate neck pain $[2,21]$.

Because direct measurement of health state preference scores can be cognitively challenging and time-consuming, there has been considerable attention to methods for deriving preference scores from conventional psychometric quality-of-life instruments [22]. Generic health status instruments have been used to measure quality-of-life in patients with musculoskeletal conditions; however, these instruments may not adequately detect dysfunction associated with neck pain. For example, a recent study determined that the SF-36 detected less disability and demonstrated less responsiveness than an upper extremity instrument in patients with upper extremity disorders, despite the fact that both instruments had comparable standardized response means [23] Neck-specific quality-oflife instruments may be more suitable for deriving preference scores in persons with neck pain, and an important step towards this goal is to explore the relationship between these two measures of HRQoL.

The primary objective of this study was to directly elicit neck pain patients' preference scores for their current health for use in a decision-analytic model and future costeffectiveness analyses. The secondary objective was to investigate the association between such preference scores and patients' level of disability related to neck pain, using a psychometrically validated disease-specific health status instrument (the Neck Disability Index), to explore the feasibility of developing a mapping algorithm between the two methods.

\section{Methods}

\section{Patient sample}

Patients were recruited from outpatient multidisciplinary rehabilitation and chronic pain clinics in two geographic regions. In California, these were consecutive persons presenting for neck pain lasting at least 3 months ('chronic neck pain' sample). In Ontario, these were consecutive persons presenting for neck pain following a motor vehicle accident (MVA) ('neck pain after a MVA' sample). Patients with neck pain caused by an identifiable aetiology (e.g., fracture, infection, tumour, inflammatory arthritide, or myelopathy), were not fluent in English, or aged $<18$ years, were excluded.

\section{Interviews}

Semi-scripted, face-to-face interviews were conducted in private rooms by trained interviewers. Selected interviews were audio-taped and reviewed for quality, particularly initial interviews conducted by each interviewer. Patients performed several tasks. First, they completed a questionnaire about their current health that was used to construct their individualized current health state description card (Appendix A). Second, they rank-ordered their current health and three short-term (4-week) and three long-term (lifetime) hypothetical health states that were pertinent to a decision analysis of neck pain treatments [24]. Third, they 
rated their current and the hypothetical health states using the RS method. Finally, their utilities to these health states were elicited using the standard gamble (SG) method. The patients' current health was framed as a short-term health state because spine pain tends to have a remitting, relapsing course $[2,17-20]$.

Health state description cards

Interviewers constructed individualized health state description cards for each patient's current health using pre-fabricated printed materials. Each patient's current health state description card was based on her/his responses to the five items contained in the questionnaire completed at the start of the interview (Appendix A). Each item corresponded to a body function, or a domain of activity and participation: (1) neck pain intensity; (2) personal care; (3) work (or school) and household chores; (4) leisure, social and family activities; and (5) emotions related to health $[25,26]$. The items had five response options that described levels of impairment or functioning. This standardized format was also used to describe the hypothetical health states, such that patients could compare their current and the hypothetical health states across uniform attributes and levels of attributes. This reduced the cognitive burden of comparing health states that differed by aetiology (i.e., musculoskeletal, cardiovascular, cerebrovascular, gastrointestinal).

\section{Rank ordering of health states}

Patients vertically ranked the health state descriptions in order of desirability. Short-term (including patients' current health) and long-term health states were rank-ordered separately. Obvious inconsistencies (such as ranking a clearly superior health state as worse than a clearly inferior state) were flagged, and patients were invited to reconsider their responses.

\section{Rating scale preference scores}

Rating scale preference scores were obtained by using a 100-point vertical visual analogue scale called a 'feeling thermometer' [27, 28]. Scores for short-term (including patients' current health) and long-term health states were obtained separately. The lowest value on the feeling thermometer was 0 (anchored by the least desirable health state) and highest value was 100 (anchored by good health). Patients placed each health state card next to the number that best represented their preference for that health state, relative to the anchor states. This number was then divided by 100 to obtain a preference score. In those patients who considered a health state to be worse than death, death and the remaining health states were assessed along a scale anchored by the health state considered worse than death and good health. These scores were then linearly transformed [29] onto the conventional death-good health $(0.0-1.0)$ preference scale using this equation:

Transformed_Score health_state $=\frac{\left(\text { Score }_{\text {health_state }}-\text { Score }_{\text {death }}\right)}{\left(1-\text { Score }_{\text {death }}\right)}$

The transformed utilities could then be pooled with the health state utilities of patients who considered death to be the worst health state.

\section{Standard gamble preference scores}

We elicited SG utility scores for the long-term (lifetime) hypothetical health states preferred to death using the conventional SG procedure. Patients were asked to consider a choice between a certainty of living in the health state under consideration for the rest of their life or a hypothetical treatment. The treatment offered a chance $(p)$ of good health (utility score $=1.0$ ) and a risk $(1-p)$ of immediate death (utility score $=0.0$ ). We used a probability wheel as a visual aid to help patients understand risks inherent in the SG $[27,28]$. The probability of the outcomes associated with the hypothetical treatment was varied using a converging ping-pong strategy until the patient was indifferent between the certainty and treatment [28]. According to decision theory, the utility of the longterm health state $h_{\mathrm{LT}}$ was equivalent to the probability of good health at this indifference point:

$h_{\mathrm{LT}}=(p)(1.0)+(1-p)(0.0)=p$

We used a slightly different procedure to elicit utilities from patients who considered a long-term health state worse than death. The hypothetical treatment offered a chance $(p)$ of good health and a risk $(1-p)$ of ending in the health state considered worse than death (rather than the risk of immediate death, as in the conventional SG described above) [7]. Under this arrangement, utilities for the long-term health states and death were assessed along a health state worse than death-good health scale. We linearly transformed these utilities onto the conventional death-good health (0.0-1.0) scale using Eq. 1 in order to pool with the long-term health state utilities of patients who considered death to be the worse health state.

We used the chained SG to elicit utilities for patients' current health (defined as a short-term health state of 4-weeks duration) and the short-term hypothetical health states (Fig. 1) [30-32]. In the first step, a short-term anchor health state $h_{\mathrm{A}}$ (considered worse than all other short-term health states) replaced immediate death (Fig. 1a, c). We described health state $h_{\mathrm{A}}$ as 'excruciating pain that is 
poorly controlled by medication while being completely dependent on others for all activities' (Appendix B). The utility of a short-term health state $h_{\mathrm{ST}}$ (including patients' current health) was then:

$h_{\mathrm{ST}}=(p)(1.0)+(1-p)\left(h_{A}\right)$

In the second step of the chained gamble, the short-term health state $h_{\mathrm{ST}}$ was related to the death-good health scale by evaluating the utility of the anchor health state $h_{\mathrm{A}}$ using the conventional SG procedure. This provided the value for $h_{\mathrm{A}}$ which was then used to solve for $h_{\mathrm{ST}}$ in Eq. 3 (Fig. 1b). In patients who considered one of the long-term health states to be worse than death, the anchor health state $h_{\mathrm{A}}$ was evaluated in relation to the long-term health state considered to be worse than death and good health (Fig. 1d) $[32,33]$. The utility of death was also assessed in relation to the health state worse than death and good health (Fig. 1e) in order to linearly transform these latter patients' utilities onto the death-good health scale, using Eq. 1.

\section{Socio-demographic and clinical variables}

Neck pain intensity was measured on a 10-centimetre visual analogue scale anchored at 'No Pain' and 'Pain as
Bad as it Could Be'. Disability related to neck pain was measured using the Neck Disability Index, a validated 10item instrument where higher scores indicate greater disability [34-36]. The Von Korff Pain Grade was used to classify neck pain and associated disability into grades of severity [37-39]. Patients also completed a co-morbidity questionnaire, [40, 41] and the 36-item Medical Outcomes Study Short Form (SF-36v2) [42, 43]. SF-6D (indirectly measured) preference scores were estimated from SF-36 data [22]. Depressive symptoms were assessed with the Center for Epidemiologic Studies-Depression (CES-D) scale [44-47], where scores $\geq 16$ suggest clinically significant depressive symptoms.

\section{Data preparation}

We deleted observations based on three pre-defined rules: (1) the interview was rated as 'Poor' or 'Very Poor' [29], which occurred whenever interviewers judged that a patient did not understand the tasks or provide thoughtful responses; (2) death was assigned a score of 1.0; or (3) preference scores were invariant at 1.0 (i.e., patients assigned a preference score of 1.0 to all the health states) [48].

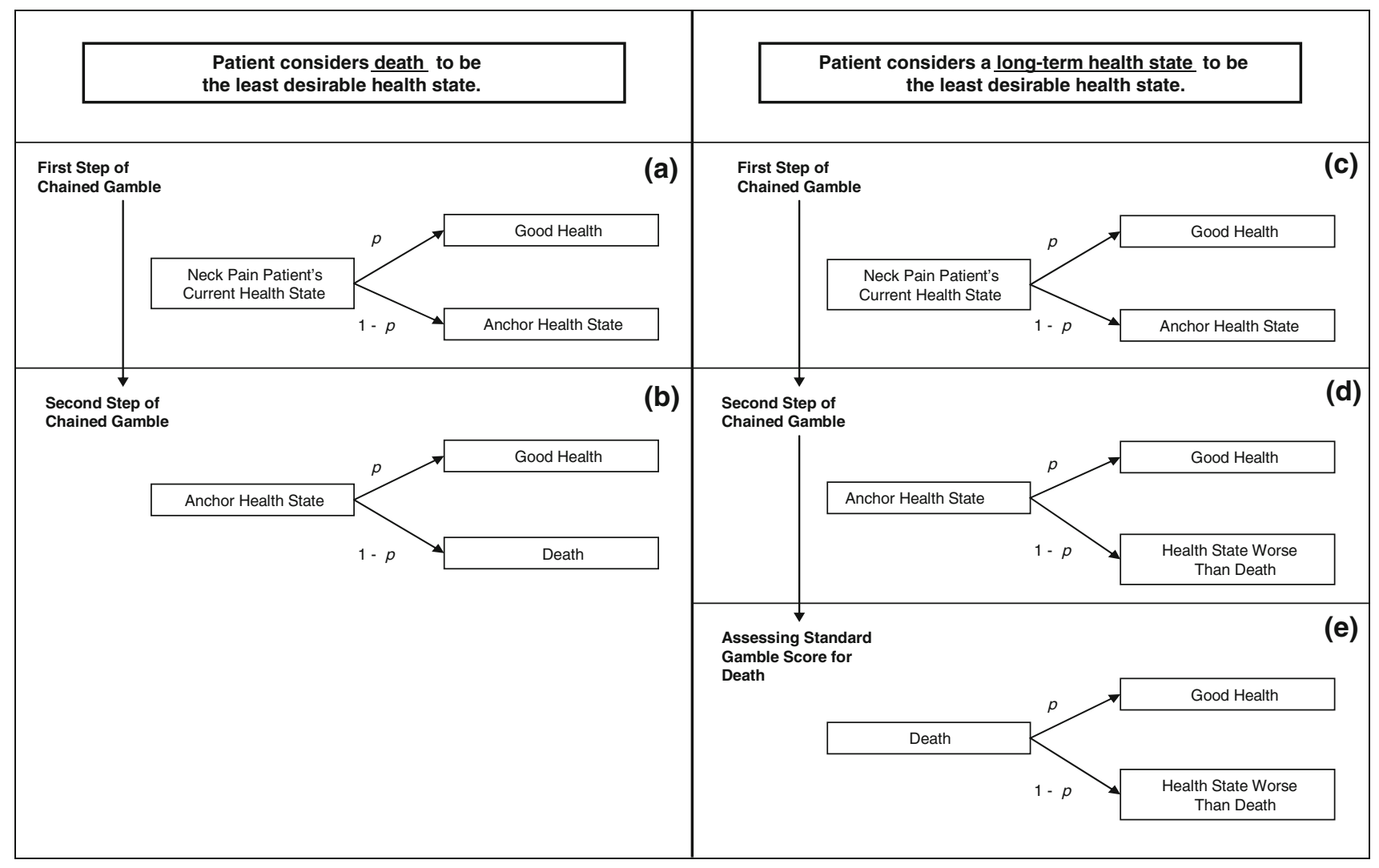

Fig. 1 Stages of the chained standard gamble procedure 


\section{Analyses}

Sample size estimate

Based on requirements for estimating mean preference scores and fitting regression models with $\leq 10$ factors [49], and predicting a loss of $10 \%$ of total observations (due to incomplete data or deletions for the above pre-defined rules), we sought to enrol 110 patients in each sample.

\section{Preference scores}

Preference scores were pooled across samples and stratified by Von Korff Pain Grades. Descriptive statistics summarized the scores within grades. An extension of Cuzick's non-parametric method was used to test for trend in preference scores across grades $[50,51]$.

\section{Explanatory regression models}

We used multivariable ordinary least squares (OLS) regression models to quantify the association between patients' directly measured preference scores for their health and their Neck Disability Index scores. Analyses were conducted on the chronic neck pain and neck pain following a MVA samples independently, to determine whether the association differed by type of neck pain. Demographic factors (age, gender) and clinical factors (neck pain duration, depressive symptoms, co-morbidity) were included in the models based on their reported associations with neck pain $[4,5,17-19,21]$.

We ran diagnostic tests on the models using conventional criteria and tested statistical assumptions for linear regression models [49, 52]. The homoscedasticity assumption was violated in the SG score models [53]. Several approaches for dealing with heteroscedasticity were applied, but none corrected the problem. We therefore fit a Tobit model as a sensitivity analysis to test the robustness of the SG score OLS model parameter estimates, since the Tobit model is used as an approach to deal with heteroscedasticity [53, 54]. All analyses were performed using SAS software (version 9.1, 2002-2003; SAS Institute, Inc., USA).

\section{Results}

\section{Patient samples}

We recruited patients from April 23, 2004 to December 21, 2005 and enrolled 104 patients with chronic neck pain and 116 patients with neck pain following a MVA (Fig. 2). All patients were interviewed within 2 weeks of their initial assessment for a course of neck pain treatment. Mean interview duration was $77 \mathrm{~min}$ (Standard Deviation $[\mathrm{SD}]=17.55)$. Patients with neck pain after a MVA tended to have lower levels of education, higher levels of neck pain intensity, and more clinically significant depressive symptoms than patients with chronic neck pain (Table 1).

Data preparation

We excluded two chronic neck pain patients from the RS score analyses, and four chronic neck pain patients and eight patients with neck pain following a MVA from the SG score analyses (Fig. 2). In patients with neck pain after a MVA, 32 of 116 patients included in the RS analyses and 26 of 108 patients included in the SG analyses considered Major Stroke Disability to be a long-term health state worse than death. In the chronic neck pain patients, 43 of 102 patients included in the RS analyses, and 41 of 100 patients included in the SG analyses considered Major Stroke Disability to be the least desirable long-term health state.

\section{Preference scores}

Neck pain patients' scores for their current health varied widely: RS scores ranged from -0.14 to 0.99 and SG scores ranged from -3.73 to 1.00 (Table 2) Negative preference scores are strictly interpreted as meaning selected patients considered their current (short-term) health to be worse than death. SF-6D scores showed less variation, ranging from 0.30 to 0.96 (Table 2). A ceiling effect was noted for SG scores, in which scores in 22 patients were equal to 1.00 (Table 2). Mean and median RS, SG, and SF-6D scores of patients with neck pain following a MVA $(\mathrm{RS}$ mean $=0.51$ $[\mathrm{SD}=0.28] ; \quad \mathrm{RS} \quad$ median $=0.51 \quad[\mathrm{IQR}=0.49] ; \quad \mathrm{SG}$ mean $=0.67 \quad[\mathrm{SD}=0.50] ; \mathrm{SG}$ median $=0.78 \quad[\mathrm{IQR}=$ 0.37]; SF-6D mean $=0.56 \quad[\mathrm{SD}=0.12]$; SF-6D median $=0.57[\mathrm{IQR}=0.14])$ were consistently lower than those of chronic neck pain patients $(\mathrm{RS}$ mean $=0.65$ $[\mathrm{SD}=0.28] ; \quad \mathrm{RS} \quad$ median $=0.70 \quad[\mathrm{IQR}=0.39] ; \quad \mathrm{SG}$ mean $=0.72 \quad[\mathrm{SD}=0.33] ; \mathrm{SG}$ median $=0.79 \quad[\mathrm{IQR}=$ 0.34]; SF-6D mean $=0.63$ [SD $=0.11]$; SF-6D med$\operatorname{ian}=0.62[\mathrm{IQR}=0.15]$ ) (Fig. 3). RS, SG, and SF-6D scores showed a gradient in the expected direction across grade of neck pain and disability (Table 2) (RS scores: $Z=[-7.42] \quad[P<0.0001] ; \quad S G$ scores: $Z=[-3.02]$ $[P=0.001]$; SF-6D scores: $Z=[-9.53][P \leq 0.0001])$.

We examined the consequence of not restricting the lower bound of the preference scales (i.e., allowing negative RS and SG scores) by setting all negative RS and SG scores to zero. This resulted in predictably higher mean and median values: $\mathrm{RS}$ mean $=0.57 \quad(\mathrm{SD}=0.29)$; $\mathrm{RS}$ median $=0.60 \quad(\mathrm{IQR}=0.53) ; \mathrm{SG}$ mean $=0.67 \quad(\mathrm{SD}=$ $0.30)$; $\mathrm{SG}$ median $=0.77(\mathrm{IQR}=0.40)$. 


\section{Patients presenting for chronic neck pain}

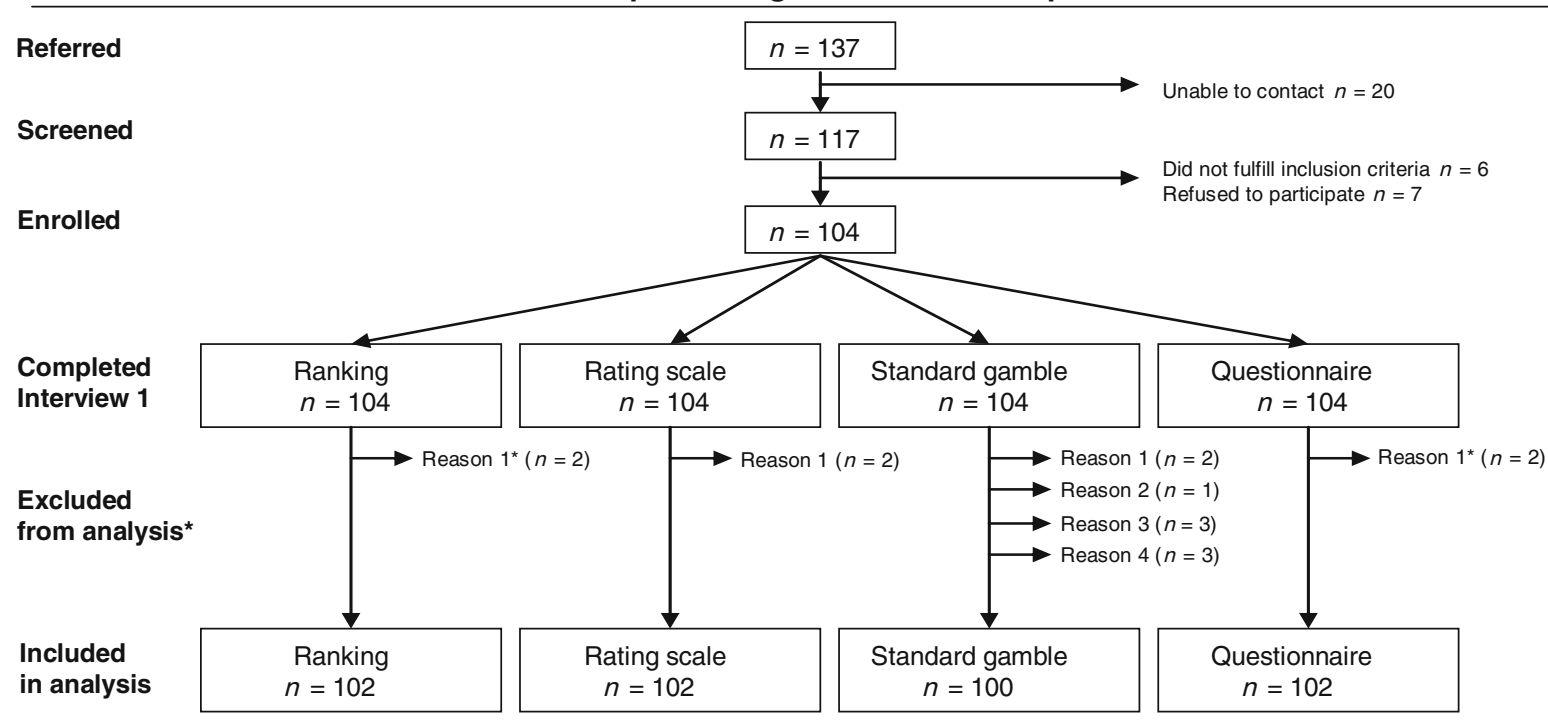

Patients presenting for neck pain following a motor vehicle accident

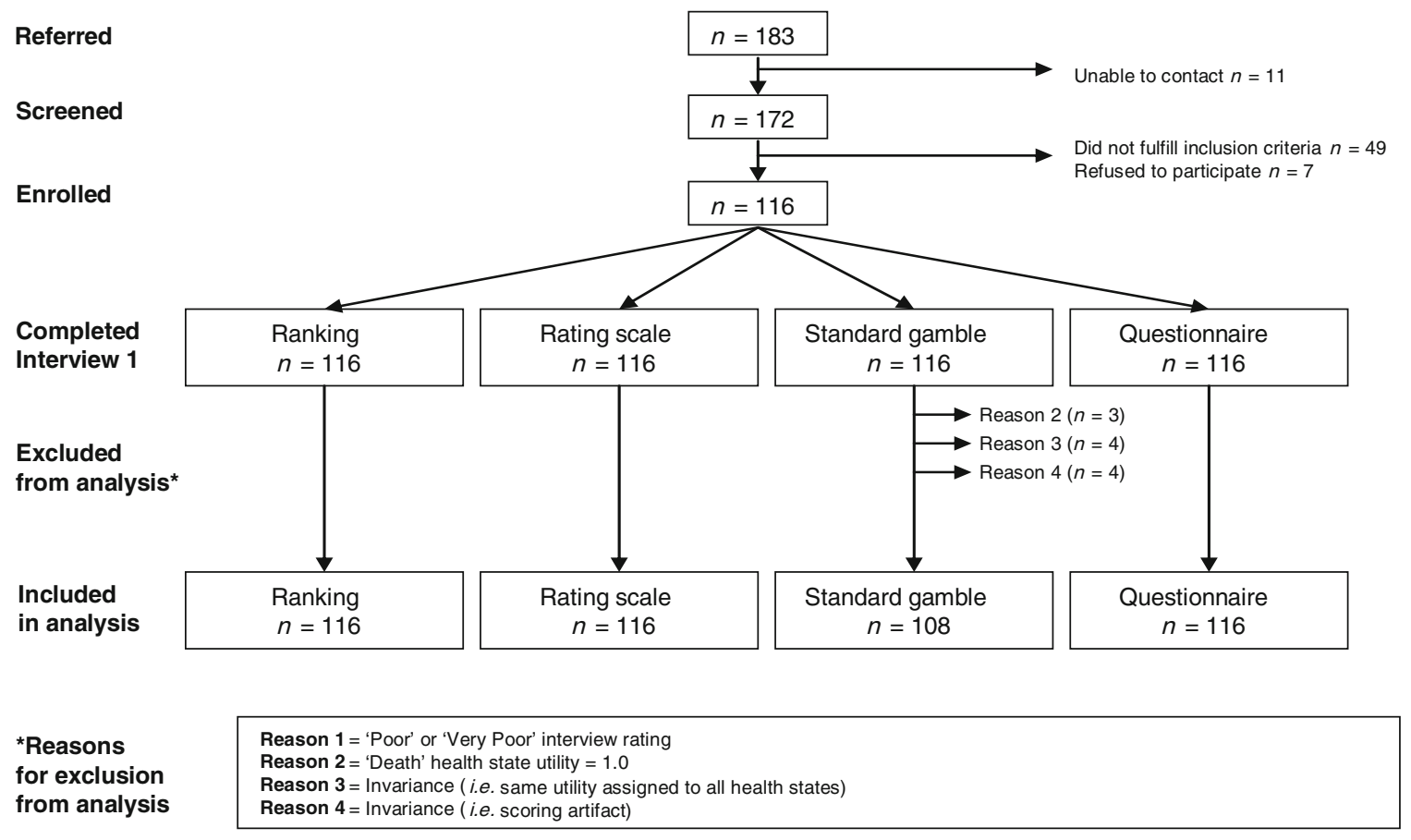

Fig. 2 Participant flow and number included in analyses. Note: in some cases, the sum of the individual $n$ for 'Reasons for exclusion from analysis' may exceed the total $n$ excluded from analyses because selected observations were excluded for more than one reason

Explanatory regression models

Tobit model parameter estimates for SG scores did not differ considerably from the overall representation given by the OLS model parameter estimates. That is, the direction, order of magnitude, and statistical significance of $\beta$ coefficients were consistent across OLS and Tobit models. We therefore focused on OLS model results for ease of comparison.

RS and SG scores that patients assigned to their current health were negatively associated with their level of neck pain disability measured by the Neck Disability Index 
Table 1 Frequencies and means for socio-demographic and clinical variables
CES center for epidemiological studies, $S D$ standard deviation, MVA motor vehicle accident

\begin{tabular}{|c|c|c|}
\hline & $\begin{array}{l}\text { Chronic neck } \\
\text { pain }(n=104)\end{array}$ & $\begin{array}{l}\text { Neck pain following } \\
\text { MVA }(n=116)\end{array}$ \\
\hline \multicolumn{3}{|l|}{ Age (SD) } \\
\hline Years & $42.2(11.4)$ & $35.4(11.4)$ \\
\hline \multicolumn{3}{|l|}{ Gender $(\%)$} \\
\hline Female & $82(78.8)$ & $79(68.1)$ \\
\hline Male & $22(21.2)$ & $37(31.9)$ \\
\hline \multicolumn{3}{|l|}{ Education $(\%)$} \\
\hline Some high school or less & $1(0.9)$ & $11(9.4)$ \\
\hline High school degree & $4(3.9)$ & $17(14.7)$ \\
\hline Some college or trade school & $20(19.2)$ & $11(9.5)$ \\
\hline College or trade school degree & $4(3.8)$ & $24(20.7)$ \\
\hline Some university & $19(18.3)$ & $19(16.4)$ \\
\hline Professional or graduate degree & $56(53.9)$ & $34(29.3)$ \\
\hline \multicolumn{3}{|l|}{ Neck pain intensity at present (SD) } \\
\hline 0-10 Centimetre visual analogue scale & $3.2(2.3)$ & $4.9(2.5)$ \\
\hline \multicolumn{3}{|l|}{ Neck Disability Index (SD) } \\
\hline $0-100$ & $31.0(16.3)$ & $42.4(19.1)$ \\
\hline \multicolumn{3}{|l|}{ Duration of current neck pain (SD) } \\
\hline Weeks & $44.6(155.6)$ & $12.6(82.5)$ \\
\hline \multicolumn{3}{|l|}{ Co-morbidity scale (SD) } \\
\hline $0-56$ & $10.9(5.8)$ & $7.9(4.6)$ \\
\hline \multicolumn{3}{|l|}{ SF-36v2 physical component scale (SD) } \\
\hline $0-100$ & $43.5(10.2)$ & $37.9(7.7)$ \\
\hline \multicolumn{3}{|l|}{ SF-36v2 mental component scale (SD) } \\
\hline $0-100$ & $42.1(11.5)$ & $38.6(11.8)$ \\
\hline \multicolumn{3}{|l|}{ CES-depression scale (SD) } \\
\hline $0-60$ & $16.7(11.5)$ & $19.6(11.6)$ \\
\hline$\geq 16$ & $45(43.3)$ & $69(59.5)$ \\
\hline
\end{tabular}

(Tables 3, 4). The magnitude of association between RS scores that chronic neck pain patients assigned to their current health and their level of disability related to neck pain changed from the crude to the adjusted model. In contrast, the magnitude of association remained consistent across crude and adjusted models in patients with neck pain following a MVA. An association was also observed between RS scores and depressive symptoms in chronic neck pain patients, but no such association was observed in patients with neck pain following a MVA. The adjusted $R^{2}$ statistic showed that the adjusted model for chronic neck pain patients explained more variance than the crude model, whereas no additional variance was explained by the adjusted model for patients with neck pain after a MVA.

There were differences across neck pain patient samples in the association between SG scores and neck pain disability as well. No association was observed in chronic neck pain patients. There was a weak, negative association observed in patients with neck pain after a MVA. As also observed in the RS-adjusted model described above, (1) the strength of the association did not change in the adjusted model for patients with neck pain following a MVA, whereas it did change in chronic neck pain patients, and (2) the adjusted model for SG scores of the chronic neck pain patients showed an association with depressive symptoms, but this did not hold for patients with neck pain after a MVA.

The adjusted $R^{2}$ statistic for both samples suggested that Neck Disability Index scores and covariates included in the SG score models collectively explained little variance beyond measurement noise. This is in contrast to the adjusted $R^{2}$ statistic values for the RS score adjusted models described above, in which at least $31 \%$ and $51 \%$ of the variance are explained in persons with chronic neck pain and those with neck pain following a MVA, respectively.

\section{Discussion}

Neck pain patients' preference scores for their current health were directly elicited using the RS and SG. Though preference scores tended to decrease as neck pain and disability increased, wide variation was observed within 
Table 2 Neck pain patients' preference scores for their current health stratified by grades of neck pain and disability

\begin{tabular}{|c|c|c|c|c|}
\hline \multirow[t]{2}{*}{ Preference scaling method } & \multicolumn{4}{|c|}{ Grades of neck pain and disability ${ }^{\mathrm{a}}$} \\
\hline & Grade I & Grade II & Grade III & Grade IV \\
\hline \multicolumn{5}{|l|}{ Rating scale } \\
\hline$n$ & 70 & 62 & 46 & 40 \\
\hline Mean (SD) & $0.76(0.21)$ & $0.60(0.26)$ & $0.44(0.27)$ & $0.39(0.26)$ \\
\hline Median (IQR) & $0.83(0.25)$ & $0.58(0.38)$ & $0.46(0.47)$ & $0.35(0.42)$ \\
\hline Minimum, maximum & $0.04,0.99$ & $0.08,0.98$ & $0.01,0.96$ & $-0.14,0.85$ \\
\hline Number $(\%)$ at ceiling & $0(0.00)$ & $0(0.00)$ & $0(0.00)$ & $0(0.00)$ \\
\hline NDI mean score (SD) & $22.77(12.39)$ & $31.94(12.98)$ & $48.98(14.92)$ & $54.13(15.26)$ \\
\hline \multicolumn{5}{|l|}{ Standard gamble } \\
\hline$n$ & 65 & 60 & 45 & 38 \\
\hline Mean (SD) & $0.81(0.22)$ & $0.70(0.34)$ & $0.64(0.29)$ & $0.57(0.78)$ \\
\hline Median (IQR) & $0.88(0.30)$ & $0.78(0.27)$ & $0.73(0.36)$ & $0.76(0.44)$ \\
\hline Minimum, maximum & $0.03,1.00$ & $-0.82,1.00$ & $-0.34,1.00$ & $-3.73,1.00$ \\
\hline Number $(\%)$ at ceiling & $10(15.39)$ & $6(10.00)$ & $2(4.44)$ & $4(10.53)$ \\
\hline NDI mean score (SD) & $22.88(12.49)$ & $31.80(13.16)$ & $48.03(14.82)$ & $54.50(15.28)$ \\
\hline \multicolumn{5}{|l|}{ SF-6D } \\
\hline$n$ & 70 & 62 & 46 & 42 \\
\hline Mean (SD) & $0.67(0.10)$ & $0.63(0.09)$ & $0.53(0.10)$ & $0.49(0.08)$ \\
\hline Median (IQR) & $0.64(0.12)$ & $0.62(0.12)$ & $0.54(0.14)$ & $0.49(0.10)$ \\
\hline Minimum, maximum & $0.40,0.96$ & $0.41,0.85$ & $0.32,0.85$ & $0.30,0.64$ \\
\hline Number $(\%)$ at ceiling & $0(0.00)$ & $0(0.00)$ & $0(0.00)$ & $0(0.00)$ \\
\hline NDI mean score (SD) & $22.77(12.39)$ & $31.94(12.98)$ & 48.98 (14.92) & $54.94(15.35)$ \\
\hline
\end{tabular}

$I Q R$ inter-quartile range, $N D I$ Neck Disability Index, $S D$ standard deviation

${ }^{a}$ Grading of neck pain and disability according to the Von Korff Pain Grade, where Grade I is pain of low-intensity and few activity limitations; Grade II is pain of high intensity, but few activity limitations; Grade III is pain associated with high levels of disability and moderate activity limitations; and Grade IV is pain with high levels of disability and several activity limitations

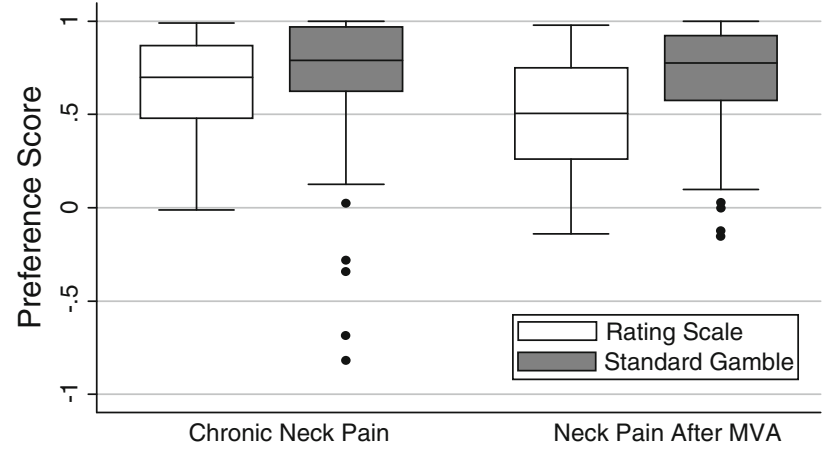

Fig. 3 Box plots of neck pain patients' preference scores for their current health. $M V A=$ motor vehicle accident. Note: a standard gamble score outlier $(-3.73)$ was removed from the neck pain after MVA group for the purpose of plotting data in this figure

grades of neck pain and disability. The association between patients' preference scores for their current health and disability related to neck pain was also investigated. A more consistent relationship was observed in patients with neck pain following a MVA compared to patients with chronic neck pain. There was also a more consistent relationship between patients' level of neck pain disability and
RS scores that they assigned to their current health, compared to SG scores. The association between preference scores and depressive symptoms was considerable in patients with chronic neck pain, whereas it was negligible in patients with neck pain after a MVA.

There are plausible explanations for these findings. Persons with acute neck pain may be more focused on their pain and disability, compared to patients with chronic neck pain who may have adapted [55]. The greater influence of depressive symptoms on chronic neck pain patients' preferences for their current health may be explained by reported associations between indicators of poor psychological health and neck pain $[4,5]$. Depressive symptoms have been associated with slower recovery from neck pain, and psychological functioning has been observed to be negatively impacted as symptom duration increases [56-58].

Our observation that a larger portion of variance was explained by disability related to neck pain in RS score regression models compared to SG score models was also observed in another study of patients with chronic musculoskeletal pain [59]. One explanation may be that the RS and Neck Disability Index share a similar response format, 
Table 3 Ordinary least squares regression model parameter estimates: persons with chronic neck pain

\begin{tabular}{|c|c|c|c|c|}
\hline & \multicolumn{2}{|c|}{ Rating scale $(n=91)$} & \multicolumn{2}{|c|}{ Standard gamble $(n=89)$} \\
\hline & $\beta$ & $95 \% \mathrm{CI}$ & $\beta$ & $95 \% \mathrm{CI}$ \\
\hline Crude model & $F=31.69$ & $P<0.0001$ & $F=1.94$ & $P=0.167$ \\
\hline Adjusted $R^{2}$ & 0.254 & & 0.011 & \\
\hline Intercept $(\alpha)$ & 92.37 & $81.79,103.09$ & 82.01 & $65.69,98.35$ \\
\hline \multicolumn{5}{|l|}{ Neck Disability Index } \\
\hline $0-100$ & -0.89 & $-1.21,-0.63$ & -0.43 & $-0.89,0.23$ \\
\hline Adjusted model & $F=6.01$ & $P<0.0001$ & $F=1.46$ & $P=0.186$ \\
\hline Adjusted $R^{2}$ & 0.308 & & 0.040 & \\
\hline Intercept $(\alpha)$ & 88.75 & $64.49,112.99$ & 97.46 & $60.37,134.55$ \\
\hline \multicolumn{5}{|l|}{ Neck Disability Index } \\
\hline $0-100$ & -0.64 & $-1.07,-0.22$ & -0.006 & $-0.68,0.67$ \\
\hline \multicolumn{5}{|l|}{ Neck pain duration } \\
\hline 0-1 Weeks (referent) & $-(-)$ & & $-(-)$ & \\
\hline 2-4 Weeks & 16.94 & $1.57,32.33$ & 3.17 & $-20.45,26.78$ \\
\hline 5-12 Weeks & 18.17 & $1.42,34.91$ & -5.18 & $-30.76,20.39$ \\
\hline$>12$ Weeks & 13.08 & $-2.39,28.55$ & 13.73 & $-9.98,37.44$ \\
\hline \multicolumn{5}{|l|}{ CES-depression scale } \\
\hline $0-60$ & -0.88 & $-1.49,-0.26$ & -1.10 & $-2.04,-0.16$ \\
\hline \multicolumn{5}{|l|}{ Co-morbidity scale } \\
\hline $0-56$ & 0.42 & $-0.72,1.55$ & 0.69 & $-1.04,2.42$ \\
\hline \multicolumn{5}{|l|}{ Age } \\
\hline 18-65 Years & -0.18 & $-0.62,0.27$ & -0.45 & $-1.13,0.23$ \\
\hline \multicolumn{5}{|l|}{ Gender } \\
\hline Female 0 , male 1 & -6.59 & $-18.77,5.59$ & -8.40 & $-27.05,10.26$ \\
\hline
\end{tabular}

Note: $\beta$ coefficients have been multiplied by 100 in this Table to facilitate their interpretation

$C I$ confidence interval

in which respondents endorse hierarchically ordered responses. In contrast, the SG requires respondents to reveal their preferences by making choices [60]. The SG score also incorporates respondents' risk attitude, through its scaling procedure which is framed in terms of uncertainty [61, 62]. Furthermore, the effects of probability transformation, contingent weighting, and loss aversion that are associated with the SG's approach of measuring utilities tend to enhance risk aversion, leading to upward bias $[31,60]$. Because there is no risk in the RS procedure, RS scores tend to be systematically lower than SG scores, as observed [63, 64].

All directly and indirectly measured mean preference scores in our study (except chronic neck pain patients' SG scores) were lower than those reported by the Beaver Dam Study (0.77 [95\% CI: 0.72, 0.81]) [15]. One explanation may be that a sizeable portion of Beaver Dam respondents may not have had neck pain when surveyed. Also, we deleted observations with invariant SG scores, and some have suggested that invariant scores account for a portion of high SG scores reported in the literature [48]. We also did not delete extreme outliers identified as points of influence, nor did we restrict the lower bound of negative preference scores. There are multiple ways to deal with influential outliers [65] and negative preference scores [66, 67], and we chose to present our data without additional deletions beyond pre-defined rules. Finally, we measured patients' preferences for their own health within a set of hypothetical health states that included a long-term health state that one-third of patients considered worse than death $[68,69]$. When we linearly transformed these patients' scores and pooled them with those of the remaining patients, overall mean scores were pulled downward.

There were other limitations associated with our study. Though our selection criteria for chronic neck pain patients included neck pain of at least 3 months duration, selected patients reported a duration of $<3$ months. This may be a measurement artefact, in which patients' current (aggravated) neck pain episode, within the fluctuating (relapsing, remitting) course of chronic neck pain, was most prominent in these patients' minds (and thus the stimulus for their response to the question on neck pain duration). Measurement error may have resulted from the manner that interviews were conducted, including the order in which health 
Table 4 Ordinary least squares regression model parameter estimates: persons with neck pain after a motor vehicle accident

\begin{tabular}{|c|c|c|c|c|}
\hline & \multicolumn{2}{|c|}{ Rating scale $(n=109)$} & \multicolumn{2}{|c|}{ Standard gamble $(n=102)$} \\
\hline & $\beta$ & $95 \% \mathrm{CI}$ & $\beta$ & $95 \% \mathrm{CI}$ \\
\hline Crude model & $F=112.99$ & $P<0.0001$ & $F=12.65$ & $P=0.0006$ \\
\hline Adjusted $R^{2}$ & 0.51 & & 0.10 & \\
\hline Intercept $(\alpha)$ & 94.89 & $85.69,104.09$ & 104.03 & $80.74,127.18$ \\
\hline \multicolumn{5}{|l|}{ Neck Disability Index } \\
\hline $0-100$ & -1.11 & $-1.29,-0.90$ & -0.90 & $-1.37,-0.40$ \\
\hline Adjusted model & $F=15.09$ & $P<0.0001$ & $F=1.77$ & $P=0.093$ \\
\hline Adjusted $R^{2}$ & 0.51 & & 0.06 & \\
\hline Intercept $(\alpha)$ & 92.17 & $72.12,112.22$ & 87.75 & $36.75,138.76$ \\
\hline \multicolumn{5}{|l|}{ Neck Disability Index } \\
\hline $0-100$ & -1.09 & $-1.33,-0.85$ & -0.86 & $-1.48,-0.24$ \\
\hline \multicolumn{5}{|l|}{ Neck pain duration } \\
\hline 0-1 Weeks (referent) & $-(-)$ & & $-(-)$ & \\
\hline 2-4 Weeks & 7.98 & $-6.02,21.98$ & 5.12 & $-32.17,42.41$ \\
\hline 5-12 Weeks & 12.31 & $-3.96,28.58$ & 20.87 & $-22.01,63.76$ \\
\hline$>12$ Weeks & -9.47 & $-31.08,12.14$ & 1.23 & $-53.84,56.31$ \\
\hline \multicolumn{5}{|l|}{ CES-depression scale } \\
\hline $0-60$ & -0.02 & $-0.42,0.38$ & -0.08 & $-1.21,1.04$ \\
\hline \multicolumn{5}{|l|}{ Co-morbidity scale } \\
\hline $0-56$ & 0.48 & $-0.58,1.53$ & 0.77 & $-1.91,3.45$ \\
\hline \multicolumn{5}{|l|}{ Age } \\
\hline 18-65 Years & -0.15 & $-0.50,0.19$ & 0.08 & $-0.81,0.97$ \\
\hline \multicolumn{5}{|l|}{ Gender } \\
\hline Female 0 , male 1 & -2.06 & $-10.44,6.33$ & 2.26 & $-19.17,23.69$ \\
\hline
\end{tabular}

Note: $\beta$ coefficients have been multiplied by 100 in this Table to facilitate their interpretation

$C I$ confidence interval

states were presented to respondents [70], and wording used to describe the health states [71]). Also, sample sizes limited the number of differences across samples that could be adjusted for. Thus, while several differences were adjusted for, there were insufficient observations to correct for all differences, including education, effect of medication, geographic region, country, and health care system.

These preference scores suggest that the HRQoL in persons seeking care for neck pain is considerably diminished. The average SG score that chronic neck pain patients assigned to their current health is nearly equivalent to mean SG scores assigned by patients with chronic, stable angina (0.81) and patients with Crohn's disease (0.79) to their own health $[72,73]$. Mean RS scores that patients with neck pain following a MVA assigned to their health are comparable to those of persons with myalgia and arthralgia from Lyme disease (0.54), while their mean SG score approaches that of Type I diabetes patients with a functioning kidney transplant $(0.72)[74,75]$. These comparisons are instructive, but not entirely valid, since neck pain patients' preferences for their episodic (short-term) health state are compared to preferences of patients with chronic (long-term) conditions.
Our study provides directly elicited preferences for health states related to chronic neck pain and neck pain following a MVA that can be used as quality-of-life weights for future decision and cost-effectiveness analyses of neck pain treatments. We also provide a preliminary examination into the feasibility of developing a mapping algorithm between directly measured neck pain patients' preferences and the most widely used neck-specific instrument: the Neck Disability Index.

Acknowledgments This study was financially supported by a joint grant provided by the Ontario Ministry of Health and Long-term Care and the Ontario Chiropractic Association. Additional funds were provided by the Bone and Joint Decade 2000-2010 Task Force on Neck Pain and Its Associated Disorders (www.nptf.ualberta.ca). Material support was provided by the Institute for Work \& Health (Toronto). Dr. van der Velde was supported by the Canadian Institutes of Health Research through a Fellowship Award and a Bisby Award. Dr. Côté was supported by the Canadian Institutes of Health Research through a New Investigator Award. Dr. Bayoumi was supported by a Career Scientist Award from the Ontario HIV Treatment Network. Dr. Krahn was supported by the F. Norman Hughes Chair in Pharmacoeconomics. The Centre for Research on Inner City Health is supported in part by a grant from the Ontario Ministry of Health and Long-term Care. The views expressed in this article are those of the 
authors, and no official endorsement by supporting agencies is intended or should be inferred.

Open Access This article is distributed under the terms of the Creative Commons Attribution Noncommercial License which permits any noncommercial use, distribution, and reproduction in any medium, provided the original author(s) and source are credited.

\section{Appendix}

\section{A: Own health questionnaire}

When answering these questions, please think about your neck pain and how it has affected your ability to do things

\section{Place a check mark in only one box for each of the sections.}

I. Neck pain
1) No pain
2) Mild pain
3) Moderate pain
4) Severe pain
5) Excruciating pain

II. Personal Care

(Think of taking a shower or a bath, dressing, combing your hair, etc.)

1) No difficulty taking care of yourself

2) Mild difficulty taking care of yourself

3) Moderate difficulty taking care of yourself

4) Severe difficulty taking care of yourself

5) Complete inability to take care of yourself

III. Work (or school) and household chores

(Think of activities related to your job, school, and maintaining your home (i.e. housework, shopping).)

1) No difficulty with work (school) or household chores

2) Mild difficulty with work (school) and/or household chores

3) Moderate difficulty with work (school) and/or household chores

4) Severe difficulty with work (school) and/or household chores

5) Complete inability to work (school) and do household chores

IV. Leisure, social, and family activities

(Think of socializing, sports, hobbies, etc.)

1) No difficulty with leisure, social, or family activities

2) Mild difficulty with leisure, social, and/or family activities

3) Moderate difficulty with leisure, social, and/or family activities

4) Severe difficulty with leisure, social, and/or family activities

5) Complete inability to do leisure, social, and family activities

V. Emotions related to your health

1) No emotional distress due to your health

2) Mild emotional distress due to your health

3) Moderate emotional distress due to your health

4) Severe emotional distress due to your health

5) Complete emotional distress due to your health 
on a day-to-day basis, during the past week. To define the 1-week period, please think about what the date was 1 week ago and recall the major events that you have experienced during this period. Focus your answers on your overall abilities, disabilities, and how you felt during the past week.

\section{B: Intermediate anchor health state description}

\section{Narrative version:}

You have excruciating pain. Pain medication partly relieves the excruciating pain. You are hospitalized for 4 weeks and are confined to a bed. As a result of this, during the 4 weeks of hospitalization you have complete inability to take care of yourself and are completely dependent on others to bathe and go to the toilet. You have complete inability to do any work and household chores, as well as engage in leisure, social, and family activities. You have severe emotional distress because of your health.

\section{Point-form version:}

Excruciating pain; Medication partly relieves excruciating pain

Hospitalization for 4 weeks

... and as a result of this, during 4 weeks of hospitalization you have:

- Complete inability to take care of yourself

- Complete inability to work (school) and do household chores

- Complete inability to engage in leisure, social, and family activities

- Severe emotional distress because of your health

\section{References}

1. Borghouts, J. A. J., Koes, B. W., Vondeling, H., \& Bouter, L. M. (1999). Cost-of-illness of neck pain in The Netherlands in 1996. Pain, 80, 629-636.

2. Côté, P., Cassidy, J. D., Carroll, L. J., \& Kristman, V. (2004). The annual incidence and course of neck pain in the general population: A population-based cohort study. Pain, 112, 267-273.

3. Côté, P., van der Velde, G., Cassidy, J. D., Carroll, L. J., HoggJohnson, S., Holm, L., et al. (2008). The burden and determinants of neck pain in workers: Results of the Bone and Joint Decade 2000-2010 Task Force on Neck Pain and Its Associated Disorders. Spine, 33, S60-S74.

4. Hogg-Johnson, S., van der Velde, G., Carroll, L. J., Holm, L., Cassidy, J. D., Guzman, J., et al. (2008). The burden and determinants of neck pain in the general population: Results of the Bone and Joint Decade 2000-2010 Task Force on Neck Pain and Its Associated Disorders. Spine, 33, S39-S51.
5. Holm, L., Carroll, L. J., Cassidy, J. D., Hogg-Johnson, S., Côté, P., Guzman, J., et al. (2008). The burden and determinants of neck pain in whiplash-associated disorders after traffic collisions: Results of the Bone and Joint Decade 2000-2010 Task Force on Neck Pain and Its Associated Disorders. Spine, 33, S52-S59.

6. Hurwitz, E. L., Carragee, E., van der Velde, G., Carroll, L. J., Nordin, M., Guzman, J., et al. (2008). Treatment of neck pain: Non-invasive interventions. Results of the Bone and Joint Decade 2000-2010 Task Force on Neck Pain and its Associated Disorders. Spine, 33, S123-S152.

7. Drummond, M. F., O'Brien, B., Stoddart, G. L., Torrance, G. W., \& Sculpher, M. (2005). Methods for the economic evaluation of health care programmes (3rd ed.). Oxford: Oxford University Press.

8. Richardson, W. S., \& Detsky, A. S. (1995). Users' guides to the medical literature. VII. How to use a clinical decision analysis. A. Are the results of the study valid? Evidence-based medicine working group. JAMA, 273, 1292-1295.

9. Richardson, W. S., \& Detsky, A. S. (1995). Users' guides to the medical literature: VII. How to use a clinical decision analysis: B. What are the results and will they help me in caring for my patients? JAMA, 273, 1610-1613.

10. Gold, M. R., Siegel, J. E., Russell, L. B., \& Weinstein, M. C. (1996). Cost-effectiveness in health and medicine. New York: Oxford University Press.

11. Lenert, L., \& Kaplan, R. M. (2000). Validity and interpretation of preference-based measures of health-related quality of life. Medical Care, 38(9 Suppl), II138-II5000.

12. Angevine, P. D., \& McCormick, P. C. (2005). Cost-effectiveness of single-level anterior cervical discectomy and fusion for cervical spondylosis. Spine, 30, 1989-1997.

13. Bell, C. M., Chapman, R. H., Stone, P. W., Sandberg, E. A., \& Neumann, P. J. (2001). An off-the-shelf help list: A comprehensive catalogue of preference scores from published cost-utility analyses. Medical Decision Making, 21, 288-294.

14. Brauer, C. A., Rosen, A. B., Greenberg, D., \& Neumann, P. J. (2006). Trends in the measurement of health utilities in published cost-utility analyses. Value in Health, 9, 213-218.

15. Fryback, D. G., Dasbach, E. J., Klein, R., Klein, B. E., Dorn, N., Peterson, K., et al. (1993). The beaver dam health outcomes study: Initial catalogue of health-state quality factors. Medical Decision Making, 13, 89-102.

16. Tengs, T. O., \& Wallace, A. (2000). One thousand health-related quality-of-life estimates. Medical Care, 38, 583-637.

17. Carroll, L. J., Hogg-Johnson, S., Côté, P., van der Velde, G., Holm, L., Carragee, E., et al. (2008). Course and prognostic factors for neck pain in workers: Results of the Bone and Joint Decade 2000-2010 Task Force on Neck Pain and Its Associated Disorders. Spine, 33, S93-S100.

18. Carroll, L. J., Hogg-Johnson, S., van der Velde, G., Haldeman, S., Holm, L., Carragee, E., et al. (2008). Course and prognostic factors for neck pain in the general population: Results of the Bone and Joint Decade 2000-2010 Task Force on Neck Pain and Its Associated Disorders. Spine, 33, S75-S82.

19. Carroll, L. J., Holm, L., Hogg-Johnson, S., Côté, P., Cassidy, J. D., Haldeman, S., et al. (2008). Course and prognostic factors for neck pain in whiplash-associated disorders: Results of the Bone and Joint Decade 2000-2010 Task Force on Neck Pain and Its Associated Disorders. Spine, 33, S83-S92.

20. Cassidy, J. D., Côté, P., Carroll, L. J., \& Kristman, V. (2005). Incidence and course of low back pain episodes in the general population. Spine, 30, 2817-2823.

21. Côté, P., Cassidy, J. D., \& Carroll, L. (2001). The treatment of neck and low back pain: Who seeks care? Who goes where? Medical Care, 39, 956-967. 
22. Brazier, J., Roberts, J., \& Deverill, M. (2002). The estimation of a preference-based measure of health from the SF-36. Journal of Health Economics, 21, 271-292.

23. Beaton, D., Erdeljan, S., Hogg-Johnson, S., \& Bombardier, C. (1995). Comparison of performance of generic SF-36 and 3 disease specific measures of health status in injured workers. Arthritis \& Rheum, 38, S175.

24. van der Velde, G., Hogg-Johnson, S., Bayoumi, A. M., Cassidy, J. D., Cote, P., Boyle, E., et al. (2008). Identifying the best treatment among common non-surgical neck pain treatments. Spine, 33, S184-S191.

25. Froberg, D. G., \& Kane, R. L. (1989). Methodology for measuring health-state preferences. I: Measurement strategies. Journal of Clinical Epidemiology, 42, 345-354.

26. World Health Organization. (2001). International classification of functioning, disability and health. World Health Organization. http://www.who.int/classifications/icf/en/

27. Froberg, D. G., \& Kane, R. L. (1989). Methodology for measuring health-state preferences-II: Scaling methods. Journal of Clinical Epidemiology, 42, 459-471.

28. Furlong, W., Feeny, D., Torrance, G., Barr, R. D., \& Horsman, J. (1990). Guide to the design and development of health-state utility instrumentation. McMaster University CHEPA Working Paper Series.

29. Torrance, G. W., Feeny, D. H., Furlong, W. J., Barr, R. D., Zhang, Y., \& Wang, Q. (1996). Multi-attribute utility function for a comprehensive health status classification system. Health Utilities Index Mark 2. Medical Care, 34, 702-722.

30. Bass, E. B., Steinberg, E. P., Pitt, H. A., Griffiths, R. I., Lillemoe, K. D., Saba, G. P., et al. (1994). Comparison of the rating scale and the standard gamble in measuring patient preferences for outcomes of gallstone disease. Medical Decision Making, 14, 307-314.

31. Jansen, S. J., Stiggelbout, A. M., Wakker, P. P., Vliet Vlieland, T. P., Leer, J. W., Nooy, M. A., et al. (1998). Patients' utilities for cancer treatments: A study of the chained procedure for the standard gamble and time trade-off. Medical Decision Making, $18,391-399$.

32. Torrance, G. W. (1986). Measurement of health state utilities for economic appraisal. Journal of Health Economics, 5, 1-30.

33. Torrance, G. W. (1987). Utility approach to measuring healthrelated quality of life. Journal of Chronic Diseases, 40, 593-603.

34. Hains, F., Waalen, J., \& Mior, S. (1998). Psychometric properties of the Neck Disability Index. Journal of Manipulative and Physiological Therapeutics, 21, 75-80.

35. Pietrobon, R., Coeytaux, R. R., Carey, T. S., Richardson, W. J., \& DeVellis, R. F. (2002). Standard scales for measurement of functional outcome for cervical pain or dysfunction: A systematic review. Spine, 27, 515-522.

36. Vernon, H., \& Mior, S. (1991). The Neck Disability Index: A study of reliability and validity. Journal of Manipulative and Physiological Therapeutics, 14, 409-415.

37. Von Korff, M., Dworkin, S. F., Le Resche, L., \& Kruger, A. (1988). An epidemiologic comparison of pain complaints. Pain, 32, 173-183.

38. Von Korff, M., Dworkin, S. F., \& Le Resche, L. (1990). Graded chronic pain status: An epidemiologic evaluation. Pain, 40, 279-291.

39. Von Korff, M., Ormel, J., Keefe, F. J., \& Dworkin, S. F. (1992). Grading the severity of chronic pain. Pain, 50, 133-149.

40. Côté, P., Cassidy, J. D., \& Carroll, L. (2000). The factors associated with neck pain and its related disability in the Saskatchewan population. Spine, 25, 1109-1117.

41. Jaroszynski, G., Cassidy, J. D., Carroll, L. J., Côté, P., \& YongHing, K. (1996). Development and validation of a comorbidity scale. Canadian Orthopedic Research Association, Quebec City, Quebec (Abstract).
42. McHorney, C. A., Ware, J. E., Jr., \& Raczek, A. E. (1993). The MOS 36-Item Short-Form Health Survey (SF-36): II. Psychometric and clinical tests of validity in measuring physical and mental health constructs. Medical Care, 31, 247-263.

43. Stewart, A. L., Hays, R. D., \& Ware, J. E., Jr. (1988). The MOS short-form general health survey. Reliability and validity in a patient population. Medical Care, 26, 724-735.

44. Blalock, S. J., DeVellis, R. F., Brown, G. K., \& Wallston, K. A. (1989). Validity of the Center for Epidemiological Studies Depression Scale in arthritis populations. Arthritis \& Rheum, 32, 991-997.

45. Clark, C. H., Mahoney, J. S., Clark, D. J., \& Eriksen, L. R. (2002). Screening for depression in a hepatitis $C$ population: The reliability and validity of the Center for Epidemiologic Studies Depression Scale (CES-D). Journal of Advanced Nursing, 40, 361-369.

46. Radloff, L. S. (1977). The CES-D Scale: A self-report depression scale for research in the general population. Applied Psychological Measurement, 1, 385-401.

47. Radloff, L. S. (1991). The use of the Center for Epidemiologic Studies Depression Scale in adolescents and young adults. Journal of Youth and Adolescence, 20, 149-166.

48. Bravata, D. M., Nelson, L. M., Garber, A. M., \& Goldstein, M. K. (2005). Invariance and inconsistency in utility ratings. Medical Decision Making, 25, 158-167.

49. Harrell, F., Jr. (2001). Regression modeling strategies with applications to linear models, logistic regression, and survival analysis. New York: Springer.

50. Cuzick, J. (1985). A Wilcoxon-type test for trend. Statistics in Medicine, 4, 87-90.

51. Pee, D., \& Freedman, L. (1990). A stratified Wilcoxin-type test for trend. Statistics in Medicine, 9, 829-834.

52. Kleinbaum, D. G., Kupper, L. L., Muller, K. E., \& Nizam, A. (1998). Applied regression analysis and other multivariable methods. Pacific Grove, CA: Brooks/Cole Publishing Company.

53. Austin, P. C., Escobar, M., \& Kopec, J. A. (2000). The use of the Tobit model for analyzing measures of health status. Quality of Life Research, 9, 901-910.

54. Tobin, J. (1958). Estimation of relationships for limited dependent variables. Econometrica, 26, 24-36.

55. Beaton, D. E., Tarasuk, V., Katz, J. N., Wright, J. G., \& Bombardier, C. (2001). "Are you better?" A qualitative study of the meaning of recovery. Arthritis \& Rheum, 45, 270-279.

56. Carroll, L. J., Cassidy, J. D., \& Côté, P. (2006). The role of pain coping strategies in prognosis after whiplash injury: Passive coping predicts slower recovery. Pain, 124, 18-26.

57. Côté, P., Hogg-Johnson, S., Cassidy, J. D., Carroll, L., \& Frank, J. W. (2001). The association between neck pain intensity, physical functioning, depressive symptomatology and time-to-claim-closure after whiplash. Journal of Clinical Epidemiology, 54, 275286.

58. Daffner, S. D., Hilibrand, A. S., Hanscom, B. S., Brislin, B. T., Vaccaro, A. R., \& Albert, T. J. (2003). Impact of neck and arm pain on overall health status. Spine, 28(17), 2030-2035.

59. Goossens, M. E., Vlaeyen, J. W., Rutten-van Molken, M. P., \& van der Linden, S. M. (1999). Patient utilities in chronic musculoskeletal pain: How useful is the standard gamble method? Pain, 80, 365-375.

60. Bleichrodt, H. (2002). A new explanation for the difference between time trade-off utilities and standard gamble utilities. Health Economics, 11, 447-456.

61. Gafni, A. (1994). The standard gamble method: What is being measured and how it is interpreted. Health Services Research, 29, 207-224.

62. Gafni, A., \& Torrance, G. W. (1984). Risk attitude and time preference in health. Management Science, 30, 440. 
63. Dolan, P., Gudex, C., Kind, P., \& Williams, A. (1996). Valuing health states: A comparison of methods. Journal of Health Economics, 15, 209-231.

64. Read, J. L., Quinn, R. J., Berwick, D. M., Fineberg, H. V., \& Weinstein, M. C. (1984). Preferences for health outcomes. Comparison of assessment methods. Medical Decision Making, 4, 315-329.

65. Fox, J. (1991). Regression diagnostics. Thousand Oaks: Sage.

66. Lamers, L. M. (2007). The transformation of utilities for health states worse than death: Consequences for the estimation of EQ-5D values sets. Medical Care, 45, 238-244.

67. Patrick, D. L., Starks, H. E., Cain, K. C., Uhlmann, R. F., \& Pearlman, R. A. (1994). Measuring preferences for health states worse than death. Medical Decision Making, 14, 9-18.

68. Llewellyn-Thomas, H., Sutherland, H. J., Tibshirani, R., Ciampi, A., Till, J. E., \& Boyd, N. F. (1982). The measurement of patients' values in medicine. Medical Decision Making, 2, 449-462.

69. Sutherland, H. J., Llewellyn-Thomas, H., Boyd, N. F., \& Till, J. E. (1982). Attitudes toward quality of survival. The concept of "maximal endurable time". Medical Decision Making, 2, 299-309.

70. Llewellyn-Thomas, H. A., \& Schwartz, C. E. (2000). Response shift effects on patients' evaluations of health states: Sources of artefact. In C. E. Schwartz \& M. Sprangers (Eds.), Adaptation to changing health: Response shift in quality of life research (pp. 109-122). Washington, DC: American Psychological Association Press.

71. Marx, R. G., Hogg-Johnson, S., Hudak, P., Beaton, D., Shields, S., Bombardier, C., et al. (2006). A comparison of patients' responses about their disability with and without attribution to their affected area. Journal of Clinical Epidemiology, 54, 580-586.

72. Arseneau, K. O., Cohn, S. M., Cominelli, F., \& Connors, A. F. (2001). Cost-utility of initial medical impairment for Crohn's disease perianal fistulae. Gastroenterology, 120, 1640-1656.

73. Kuntz, K. M., Fleischmann, K. E., Hunink, M. G., \& Douglas, P. S. (1999). Cost-effectiveness of diagnostic strategies for patients with chest pain. Annals of Internal Medicine, 130, 709-718.

74. Kiberd, B. A., \& Larson, T. (2000). Estimating the benefits of solitary pancreas transplantation in nonuremic patients with Type I diabetes mellitus: A theoretical analysis. Transplantation, 70, $1121-1127$.

75. Shadick, N. A., Liang, M. H., Phillips, C. B., Fossel, K., \& Kuntz, K. M. (2001). The cost-effectiveness of vaccination against Lyme disease. Archives of Internal Medicine, 161(4), 554-561. 